\title{
Editorial on the manuscript entitled "Impact of Troponin I-Autoantibodies in Chronic Dilated and Ischemic Cardiomyopathy" by Andreas O. Doesch and co-workers
}

\author{
Stephan B. Felix
}

Received: 6 December 2010/Accepted: 6 December 2010/Published online: 15 December 2010

(C) Springer-Verlag 2010

Despite advances in medical treatment, the prognosis of heart failure due to left ventricular systolic dysfunction is poor. In many cases in which disease progression cannot be inhibited by pharmacotherapy, heart transplantation remains the only therapeutic option. The most common causes of heart failure due to myocardial diseases are coronary heart disease, valve diseases, and cardiomyopathies [4]. Dilated cardiomyopathy (DCM) is the third most common cause of heart failure and the most frequent reason for heart transplantation [18]. This myocardial disease is characterized by ventricular chamber enlargement and progressive systolic dysfunction. In approximately 20-35\% of DCM cases, a genetic background has been reported [18]. In addition, both experimental and clinical data indicate that viral infection and inflammatory processes may be involved in the pathogenesis of DCM [3, 6, 11, 27]. Abnormalities of the cellular immune system are a common feature of myocarditis and DCM. For patients with DCM, immunohistological methods have been introduced for diagnosis of myocardial inflammation. The term "inflammatory cardiomyopathy" has therefore been coined to describe the etiology of acquired cardiomyopathy [18]. Infiltrations with lymphocytes and mononuclear cells, as well as increased expression of cell adhesion molecules, are frequent phenomena in DCM [14, 21, 26]. These findings support the hypothesis that the immune process is still active.

Patients with myocarditis and DCM demonstrate abnormalities of the humoral immune system as well. Furthermore,

\section{S. B. Felix $(\square)$}

Klinik für Innere Medizin B,

Ernst-Moritz-Arndt-Universität Greifswald,

Friedrich-Loeffler Str. 23a, 17475 Greifswald, Germany

e-mail: felix@uni-greifswald.de various autoantibodies have been detected in DCM patients: these include antibodies against mitochondrial proteins [23], cardiac myosin [2], cardiac $\beta_{1}$-adrenergic receptors [25], muscarinergic receptors [8], and the sarcolemmal Na-K-ATPase [1]. The functional role of cardiac autoantibodies in DCM is under debate. Antibodies may reflect an inflammatory response to myocyte necrosis, thereby representing an epiphenomenon or, alternatively, may play an active role in the disease process. In patients with chronic myocarditis and cardiomyopathy, the prevalence of antibodies against cardiac myosin is associated with the deterioration of cardiac function [15]. Experimental data indicate that certain cardiac autoantibodies may play a functional role in DCM: antibodies against the ADP/ATP carrier interact with the calcium channel and possess cardiotoxic properties [23]. In the plasma of patients with DCM, negative inotropic antibodies are detectable that decrease the calcium transients of isolated cardiomyocytes [7]. A recent study by Li et al. [17] demonstrated that anti-cardiac myosin antibodies induced by immunization of rats with cardiac myosin target the $\beta$-adrenergic receptor on the heart cell surface. Passive transfer of purified antibodies from cardiac myosinimmunized rats results in $\mathrm{IgG}$ deposition and apoptosis in the heart, leading to a cardiomyopathic heart disease phenotype in recipients.

Immunization of rodents against peptides derived from cardiovascular G-protein receptors induces morphological changes of myocardial tissue resembling DCM [9, 19]. A recent study by Jahns et al. [12] investigated the pathogenic significance of autoantibodies that target cardiac $\beta_{1}$-adrenoceptors in DCM: rats immunized against the second extracellular loop of cardiac $\beta_{1}$-receptors developed progressive left-ventricular dilatation and dysfunction. Sera transferred from these immunized animals to unsensitized 
rats induced a similar cardiomyopathic phenotype, thus demonstrating the pathogenic potential of a particular antibody for development of DCM. Further confirmation of the principle that autoantibodies contribute to induction of the disease process and to progression to DCM has been provided in a study by Nishimura et al [20]. The authors of this study showed that mice deficient in the programed cell death-1 (PD-1) immunoinhibitory coreceptor develop autoimmune DCM with production of high-titer circulating IgG autoantibodies reactive to a $33-\mathrm{kDa}$ protein expressed specifically on the sarcolemma of cardiomyocytes. Okazaki et al. [22] were recently able to identify this antigen as cardiac troponin I (cTNI). Interestingly, transfer of cTNI-specific T cells induces inflammation and fibrosis in wild-type mice [13]. Furthermore, cTNI—but not cardiac troponin $\mathrm{T}$-induces severe inflammation in the myocardium followed by fibrosis and heart failure, with increased mortality in mice [10]. The question arises whether release of cTNI into the circulation after damage or cell death of cardiomyocytes due to various aetiologies will likewise induce the production of auto-antibodies against cardiac troponin I. Interestingly, a recent study investigated the clinical relevance of detected antibodies to cTNI (cTNI-ab) in patients after acute myocardial infarction [16]. Absence of cTNI-ab predicts improvement of left ventricular function after acute myocardial infarction, whereas no significant increase in LVEF was seen in cTnI-ab-positive patients.

These above experimental and clinical data indicate that antibodies against cardiac epitopes may play a causal role in the development of myocardial diseases, rather than being epiphenomena. In this matter, investigations of the prognostic value of circulating TNI-autoantibodies in plasma of patients with chronic heart failure are of particular scientific interest. In this issue of the Journal, Doesch et al. [5] present data on the impact of autoantibodies to troponin I (TNI) in chronic dilated and ischemic cardiomyopathy.

The authors tested sera of 249 patients with dilated cardiomyopathy (DCM) and 141 patients with ischemic cardiomyopathy (ICM) for the presence of antibodies to TNI (TNI-ab) by a customized enzyme-linked immunosorbent assay. The primary aim of the study was to ascertain whether there was an association of detection of TNI-ab with the combined end-point of death $(n=118$, $30.3 \%$ of total) or heart transplantation. Subgroup analysis showed a favorable outcome in TNI-ab-positive patients with heart failure if the patients suffered from DCM, whereas TNI-ab status in patients with ICM was not associated with survival. Multivariate analysis in DCM patients showed that a negative TNI-ab serostatus was still an independent risk associated with higher all-cause mortality reaching borderline significance $(p=0.0492)$. From the data of the present study, the authors deduce that in DCM patients the presence of TNI-ab is associated with improved survival, whereas detection of TNI-ab has no association with prognosis in ischemic cardiomyopathy. The authors conclude that TNI-ab may be protective in DCM.

The study by Doesch et al. [5] clearly contrasts with most experimental and clinical data published until now. As the authors of the present study rightly mention, all experimental data suggest detrimental effects of TNI-ab. Antibodies to cTNI induce heart dysfunction and ventricular dilatation [20]. Subsequent animal studies found that immunization with cTNI, but not troponin T, leads to myocardial inflammation and a DCM-like phenotype [22]. Clinical studies point in the same direction: patients with acute myocardial infarction and cTnI-ab detection had significantly worse LVEF when compared to cTNI-abnegative patients [16]. Based on these findings, speculation may arise that exposure of cardiac proteins such as myosin or cTNI to the circulation and, subsequently, to the immune system initiates production of cardiac antibodies that induce myocardial damage.

Why does the present study fail to support most of the published data? Is it justified to conclude from the present data that TNI antibodies are unexpectedly protective in DCM? To begin, one potential strength of the study by Doesch et al. [5] is the high number of patients included into this monocentric analysis. However, tempting as it may be, conclusions should not be heedlessly drawn from the present study, e.g., concerning a protective role of antibodies. Additional analysis of cardiovascular mortality may have been appropriate to ascertain potential (cardio)protective effects of cTNI-ab in DCM. The small number of autoantibody-positive patients with ICM and DCM (42 patients with DCM and 31 patients with ICM) may inhibit analysis of the outcome of these subgroups. Association of negative auto-antibody status with all-cause mortality was of borderline significance in multivariate analysis $(p=0.049)$. Moreover, clinical data at baseline differed between the two patient groups. The ICM group was not aged-matched to the DCM group, which impedes the comparison of the two groups. One criterion for inclusion of ICM patients was left-ventricular ejection fraction less than 55\%. Some patients of this cohort may therefore have had almost normal LV function although LV function at baseline was not different from patients with DCM. Furthermore, no healthy control group was chosen for comparison of antibody status in patients.

There are some other points that should be considered concerning interpretation of the data. The ELISA method may entail several shortcomings: in estimating an antibody titer, one usually assumes homogeneous binding of the respective antibody to the solid phase, despite reports in 
the literature that this may be not true [24]. Determining the optimum cut-off point and the manner of accounting for positive and negative control values are problematic. Moreover, the immunologic response is polyclonal, and at least two epitopes of cTnI can induce myocardial damage in murine models [13]. The exact binding site of the troponin antibodies measured in the present study remains unclear.

Finally, this study does not contain mechanistic data that support the conclusion that TNI-ab are protective in DCM. Hence, as the authors rightly mention, a potential protective role of TNI-ab is still based on speculation. Further studies that provide mechanistic data are required to support the hypothesis that TNI-ab are protective in DCM. Nevertheless, this provocative study challenges the hypothesis that a particular antibody plays a causal pathophysiological role in cardiac dysfunction in DCM. These data require confirmation by both clinical and experimental findings.

\section{References}

1. Baba A, Yoshikawa T, Ogawa S (2002) Autoantibodies produced against sarcolemmal Na-K-ATPase: possible upstream targets of arrhythmias and sudden death in patients with dilated cardiomyopathy. J Am Coll Cardiol 40:1153-1159

2. Caforio AL, Grazzini M, Mann JM, Keeling PJ, Bottazzo GF, McKenna WJ, Schiaffino S (1992) Identification of alpha- and beta-cardiac myosin heavy chain isoforms as major autoantigens in dilated cardiomyopathy. Circulation 85:1734-1742

3. Dec GW, Palacios IF, Fallon JT, Aretz HT, Mills J, Lee DC, Johnson RA (1985) Active myocarditis in the spectrum of acute dilated cardiomyopathies. Clinical features, histologic correlates, and clinical outcome. N Engl J Med 312:885-890

4. Dickstein K, Cohen-Solal A, Filippatos G, McMurray JJV, Ponikowski P, Poole-Wilson PA, Strömberg, van Veldhuisen DJ, Atar D, Hoes AW, Keren A, Mebazaa A, Nieminen M, Priori SG, Swedberg K (2008) ESC Guidelines for the diagnosis and treatment of acute and chronic heart failure 2008. Developed in collaboration with the Heart Failure Association of the ESC (HFA) and endorsed by the European Society of Intensive Care Medicine (ESICM). Eur Heart J 29:2388-2442

5. Doesch AO, Mueller S, Nelles M, MD1, Konstandin M, Sultan Celik, Frankenstein L, Goeser S, Kaya Z, Koch A, Zugck C, Katus HA (2010) Impact of troponin I-autoantibodies in chronic dilated and ischemic cardiomyopathy. Basic Res Cardiol (in press)

6. Feldman AM, McNamara DM (2000) Myocarditis. New Engl J Med 343:1388-1398

7. Felix SB, Staudt A, Landsberger M, Grosse Y, Stangl V, Spielhagen T, Wallukat G, Wernecke K-D, Baumann G, Stangl K (2002) Removal of cardiodepressant antibodies in dilated cardiomyopathy by immunoadsorption. J Am Coll Cardiol 39:646-652

8. Fu ML, Magnusson Y, Bergh CH, Liljeqvist JA, Waagstein F, Hjalmarson A, Hoebeke J (1993) Localization of a functional autoimmune epitope on the muscarinic acetylcholine receptor-2 in patients with idiopathic dilated cardiomyopathy. J Clin Invest 91:1964-1968
9. Fu ML, Schulze W, Wallukat G, Hjalmarson A, Hoebeke J (1996) A synthetic peptide corresponding to the second extracellular loop of the human M2 acetylcholine receptor induces pharmacological and morphological changes in cardiomyocytes by active immunization after 6 months in rabbits. Clin Immunol Immunopathol 78:203-207

10. Göser S, Andrassy M, Buss SJ, Leuschner F, Volz CH, Öttl R, Zittrich S, Blaudeck N, Hardt SE, Pfitzer G, Rose NR, Katus HA, Kaya Z (2006) Cardiac troponin I but not cardiac troponin $T$ induces severe autoimmune inflammation in the myocardium. Circulation 114:1693-1702

11. Huang C-H, Vallejo JG, Kollias G, Mann DL (2009) Role of the innate immune system in acute viral myocarditis. Basic Res Cardiol 104:228-237

12. Jahns R, Boivin V, Hein L, Triebel S, Angermann CE, Ertl G, Lohse MJ (2004) Direct evidence for a beta1-adrenergic receptordirected autoimmune attack as a cause of idiopathic dilated cardiomyopathy. J Clin Invest 13:1419-1429

13. Kaya Z, Göser S, Buss SJ, Leuschner F, Öttl R, Li J, Völkers M, Zittrich S, Pfitzer G, Rose NR, Katus HA (2008) Identification of cardiac troponin I sequence motifs leading to heart failure by induction of myocardial inflammation and fibrosis. Circulation 118:2063-2072

14. Kühl U, Noutsias M, Schultheiss HP (1995) Immunohistochemistry in dilated cardiomyopathy. Eur Heart J 16(Suppl O): $100-106$

15. Lauer B, Schannwell M, Kühl U, Strauer BE, Schultheiss HP (2000) Antimyosin autoantibodies are associated with deterioration of systolic and diastolic left ventricular function in patients with chronic myocarditis. J Am Coll Cardiol 35:1106-1110

16. Leuschner F, Li J, Göser S, Reinhardt L, Öttl R, Bride P, Zehelein J, Pfitzer G, Remppis A, Giannitsis E, Katus HA, Kaya Z (2008) Absence of auto-antibodies against cardiac troponin I predicts improvement of left ventricular function after acute myocardial infarction. Eur Heart J 29:1949-1955. doi:10.1093/eurheartj/ ehn268

17. Li Y, Heuser JS, Cunningham LC, Kosanke SD, Cunningham MW (2006) Mimicry and antibody-mediated cell signaling in autoimmune myocarditis. J Immunol 177:8234-8240

18. Maron BJ, Towbin JA, Thiene G, Antzelevitch C, Corrado D, Arnett D, Moss AJ, Seidman CE, Young JB (2006) Contemporary definitions and classification of the cardiomyopathies: an American Heart Association Scientific Statement from the Council on Clinical Cardiology, Heart Failure and Transplantation Committee; Quality of Care and Outcomes Research and Functional Genomics and Translational Biology Interdisciplinary Working Groups; and Council on Epidemiology and Prevention. Circulation 113:1807-1816. doi:10.1161/CIRCULATIONAHA. 106.174287

19. Matsui S, Fu ML, Katsuda S, Hayase M, Yamaguchi N, Teraoka K, Kurihara T, Takekoshi N, Murakami E, Hoebeke J, Hjalmarson A (1997) Peptides derived from cardiovascular G-proteincoupled receptors induce morphological cardiomyopathic changes in immunized rabbits. J Mol Cell Cardiol 29:641-655

20. Nishimura H, Okazaki T, Tanaka Y, Nakatani K, Hara M, Matsumori A, Sasayama S, Mizoguchi A, Hiai H, Minato N, Honjo T (2001) Autoimmune dilated cardiomyopathy in PD-1 receptor-deficient mice. Science 291:319-322

21. Noutsias M, Seeberg B, Schultheiss HP, Kühl U (1999) Expression of cell adhesion molecules in dilated cardiomyopathy: evidence for endothelial activation in inflammatory cardiomyopathy. Circulation 99:2124-2131

22. Okazaki T, Tanaka Y, Nishio R, Mitsuiye T, Mizoguchi A, Wang J, Ishida M, Hiai H, Matsumori A, Minato N, Honjo T (2003) Autoantibodies against cardiac troponin I are responsible for 
dilated cardiomyopathy in PD-1-deficient mice. Nat Med 9:1477-1483. doi:10.1038/nm955

23. Schultheiss HP, Kühl U, Janda I, Melzner B, Ulrich G, Morad M (1988) Antibody-mediated enhancement of calcium permeability in cardiac myocytes. J Exp Med 168:2102-2119

24. Underwood PA (1993) Problems and pitfalls with measurement of antibody affinity using solid phase binding in the ELISA. J Immunol Methods 164:119-130

25. Wallukat G, Wollenberger A, Morwinski R, Pitschner HF (1995) Anti-beta1-adrenoceptor autoantibodies with chronotropic activity from the serum of patients with dilated cardiomyopathy: mapping of epitopes in the first and second extracellular loops. J Mol Cell Cardiol 27:397-406
26. Wojnicz R, Nowalany-Kozielska E, Wodniecki J, Szczurek-Katanski K, Nozynski J, Zembala M, Rozek MM (1998) Immunohistological diagnosis of myocarditis. Potential role of sarcolemmal induction of the MHC and ICAM-1 in the detection of autoimmune mediated myocyte injury. Eur Heart J 19:15641572

27. Zimmermann O, Bienek-Ziolkowski M, Wolf B, Vetter M, Baur R, Mailänder V, Hombach V, Torzewski J (2009) Myocardial inflammation and non-ischaemic heart failure: is there a role for C-reactive protein? Basic Res Cardiol 104:591-599. doi:10.1007/ s00395-009-0026-2 